\title{
The Important Role of New Technologies in Supporting Roller Hockey Referees
}

\author{
Inês Cadavez ${ }^{1}$, Abílio Oliveira $^{1,2}$ \\ ${ }^{1}$ ISCTE - Instituto Universitário de Lisboa, ${ }^{2}$ ISTAR-Iscte, Lisboa \\ Portugal
}

\begin{abstract}
Technology is increasingly present in everyday life. All people are users of technology, and the world of sports is no exception. Indeed, there is a strong need for task improvement, and, in sports practice, the implementation of technologically advanced tools is a reflection of the execution of that objective, as athletes, coaches, referees, or fans, are involved in that process. However, roller hockey, which is considered an old and traditional sport, is out of sync with this new reality. Thus, one may tackle the main issue to evaluate the importance of technology according to the perceptions of the different stakeholders involved in the Roller Hockey sport. Using questionnaires, we intend to characterize the perceptions regarding available technologies and potential applications. In this paper, some results of this study $(N=227)$ are presented so that the potential for introducing information technologies to the referee role may be understood.
\end{abstract}

\section{Introduction}

The Portuguese Roller Hockey team is highly known, both in the national and international sports arenas, and is the present winning in the 2019 World Championships. This is the most awarded sport for Portugal, nationally, and club wise [2].

Science application is one of the most influential changes affecting the evolution of sports around the world, as the ever-increasing performance of technology, supported by scientific data, is enabling the implementation of register and analysis frameworks into the reality of the sports [8].

Once Roller Hockey is regarded as a traditional sport but with historical achievements driving the increasing number of fans, it is paramount that it may keep up with the technological evolution in order to emphasize its rigor, ethics, and transparency values. Although there are no consistent studies regarding the present characteristics of the Roller Hockey sport, it is the common opinion among its coaches that this sport has become quicker, more tactical, and each game's success more dependent on the superb rink positioning of each team [17]. Therefore, it is vital to understand the perspective and perceptions of all entities involved in Roller Hockey regarding the importance and urgency of technology implementation, together with the assessment of its impact in the organization, work, and data collection activity of the several functions responsible for this sport.

Thusly, herewith is presented part of a paper being developed for a master's degree dissertation (on IS Management), which aims to address the following issue: "What is the importance of the information technologies in the support to the referee function in Roller Hockey? This document focus specifically on three sub-items (a) Understand the impact of technology already deployed in this sport, (b) The perceived opportunities of additional features already used in other sports, and (c) Evaluate the degree of acceptance of implementing an information system for the referee role.

The results presented result from a questionnaire developed upon a deep literature and practice study and presented through the online platform Qualtrics to be answered by referees and other stakeholders involved in Roller Hockey.

\section{Literature Review}

\subsection{Sports evolution and digitalization}

The sport is a global phenomenon that mobilizes numerous sectors of activity and is based on the physical activity that praises competition, usually conditioned by rules and in which one's morale and character are highlighted [14].

According to a researcher at the University of Coimbra, the sport has become one of Portugal's most relevant social phenomena, imbibed in a large and complex associative, institutional, political, economic, mediatic, and ideological network [16]. There is a growing number of athletes, clubs, and referees in the country. According to PORDATA site (Portugal contemporary database), during the period from 1997 to 2018, the number of athletes has increased from 271.470 to 667.715 individuals, and the number of referees has gone from 9.470 to 15.618 . Roller Hockey has experienced the same trend, as the number of registered players has grown from 1.215 to 2.135. Running alongside this increase in sports activity, technology is becoming ever more integrated into our society's daily activities, and it has changed 
both the knowledge acquisition and transmission processes. However, it is compelling the lack of technology applications to sports-related knowledge [20]. Although information technology evolution is essential for all sectors, it is vital for the sports industry [10]. The development of new technologies and innovation is crucial in sports management, as innovation targets the development, optimization, and customization of products, systems, and services [14]. Sports organizations will continue to be engaged in effective and efficient technology adoption, which will improve individual, collective and organizational development [3].

The sports performance "limits" have been continuously surpassed along with its history. An enormous contribution for that has come from technology, namely applied to better sports equipment, exercise methodologies sophistication, coaches training enhancement, and the superior knowledge of the human organism functioning when practicing sports activity.

The application of technology to the sports environment is increasingly relevant to the evolution of athletes seeking a technical or physical edge that enables them to improve their performance towards overcoming individual limits and records breaking [20].

Technology can significantly enhance the observation and analysis processes' quality and speed, as long as it is used appropriately [7]. The use of timeconsuming methods for data processing can be avoided when he addresses the present technology degree of sophistication [18], and three main factors influence the general adoption of technological innovations: cost, user-friendliness, and reliability [11]. On the other hand, the technology affects sports in many ways, and that its implementation to the sports world enables the decrease of incidents during the referees' judgment of the players' moves [4]. The efficiency and yield are generated and fed by the technical and technological evolution [6].

There are several sports where technology is already deeply rooted, like football, which is considered the most popular sport globally [13], tennis, and volleyball. The technological possibility spectrum in football is still to be fully tackled [15]. However, there are several technologies already in use: VAR (video assistant referee) - the technology which aims to minimize potential errors incurred by the referee team when judging controversial game situations; LGT (line of goal technology), which purpose is to help the referee team, while not constraining the referees' decision-making process to the technological system; and the SCOUT - a software tool that translates the game moves into virtual interactions, in order to generate statistical data to be used by all the professionals involved in football, such as coaches and physical trainers, together with the enhancement of information to media reporters and fans watching the game in real-time on TV [20].

In tennis, the Hawk-eye is the most relevant technology in use, helping the referee in the decisionmaking process. This system can capture both the ball trajectory and the positioning of various objects and people from different angles, enabling the mitigation of controversial decisions by the referee team, especially in somewhat questionable calls [19].

In volleyball, there is a system called Penalty dTech, which, based on video cameras, aerials, and a chip in the ball, allows the visualization on a screen of the game moves with enhanced detail. In a nutshell, we have seen increasing use of technology among several sports areas in recent years, although not always as a helping tool for the referee teams, but rather more focused on the external users, coaches, and other parties involved [12].

\subsection{The impact of the technology on Roller Hockey}

The Roller Hockey original roots are rather ancient. Historical records show that a rudimental type of hockey was practiced in Egypt 4.000 years ago and Ethiopia around the year 1.000 BC [1]. Other sources report that its origin comes from discovering an Egyptian bas-relief where several children are portrayed playing ball with some thick batons [1].

Regarding Portugal, it is common ground thinking that Roller Hockey had its origin from the game of Choca. That game was played by five players equipped with a stick (which could or not be curved at the tip), a small wooden ball (or a pine) named reca, choca, or porca [1]. It settled in 1915 with its practicing at Amadora, led by an Englishman named Arthur Vleeschover [9].

In Europe, as skating became a sporting reality with its three disciplines (speed skating, figure skating, and skating hockey) along the 20th century, there was an increasing need to organize it. After the end of world war II, the Iberian countries (Portugal and Spain) began to dominate skating hockey, both in the European and the Worldwide stages [1].

The big roller hockey promotion happened during the $40 \mathrm{~s}$, through the radio and newspapers media acclamation of the Portuguese athletes as the best in the World [9].

Nowadays, roller hockey is practiced in 60 countries, and one may anticipate it will grow more significantly soon, as there is the expectation that this sport may be again part of the Olympics, as it once was in the Barcelona, 1992 Olympic Games.

The Rink-Hockey European Committee (CERH Comité Européen de Rink-Hockey) has been changing the game rules for years to make it more attractive. In 2009/2010, those changes made it more similar to Ice Hockey, namely by introducing rules that create power-play situations to mitigate the 
referee tolerance towards physical contact among players.

Roller Hockey is regarded as one of the most complex team sports, as it demands from its players not only high technical and tactical skills but also psychological preparation and a continuously high degree of physical development and improvement [5]. This sport is performed by two teams, with all its players wearing roller-skates to move around while maneuvering a ball with a tool (stick), not being allowed to influence the ball with any part of their bodies, except for the goalkeeper. On top of the rollerskates and the stick, the goalkeeper has a specific outfit geared for the task. Roller Hockey is a situational sport, as its technical execution is contingent upon the competition's agonistic conditions and the opponent's positioning on the rink [17].

The present discipline has broad importance and recognition in Portugal, both in the national and international sporting scenes, due to the success that this sport has achieved over the years [5]. It also refers that Portugal is the most successful national roller hockey team, both in the European (44 medals) and World (42 medals) championships [2].

Roller Hockey is considered a traditional [9], fastmoving sport, with players' need to possess specific physical characteristics. A limited number of rudimental technologies are used to help the referee jobAa chronometer, a 45 seconds marker, earpiece es for referees' intercommunication, and an electronic type of bulletin. Outside the rink, it has been recently implemented another technology, Fluidsports, by the top league team UD Oliveirense, aimed at helping the goalkeeper's training. It is not known any other technical evolution to be in use beyond those.

Porto University has been engaged in several studies aiming to improve the roller hockey equipment to modernize its practice. For instance, new technology was developed to apply electronic devices to the hockey sticks so that a broad range of data regarding passes, goal shots, game duration, and ball speed estimation can be collected. This device consists of some sensors, a memory, and one microprocessor, communicating wirelessly with a smartphone to register the players' performance. The goal is to improve the handling of the stick, as it is a crucial game instrument. When used together with other present technologies, this enables the athletes to understand their individual shot quality, stick handling skills, and flaws, thanks to the collection and record of correlated data, which will ultimately improve the athletes' performance.

\section{Research Question and Objectives}

The application of technology to many areas, namely to sports, has significantly impacted performance and results in improvement, either through systems or software. Having this reality in mind when addressing Roller Hockey, a traditional sport usually disconnected from the existent technological environment, it is relevant to understand how the technology impacts and influences the role of the Roller Hockey referee. Hence, this paper's motto is: "What is the importance of the information technologies supporting the referee function in Roller Hockey?

Thus, there are three main objectives that we target to address:

1. To understand the impact of the technology already deployed in this sport;

2. To perceive the potential and possibilities of additional applications, already in use in other sports;

3. To verify the degree of acceptance of an information system for the referee team.

\section{Methodology}

This study had 227 participants $(\mathrm{N}=227)$, cataloged into five groups - referees, athletes, coaches, managers, and fans -, with ages ranging from 16 to 78 years old; as the referees are the leading focus group, 72 Roller Hockey Portuguese referees answers were collected $(\mathrm{N}=72)$, corresponding to $33 \%$ of the sampled universe.

The referees were characterized by having a high average age (43 years old), mainly belonging to the masculine genre (96\%), and having an academic background lower than the rest of the individuals questioned; only $20 \%$ had a college degree, and referees represented $63 \%$ of the participants having only basic school studies.

A questionnaire was developed based on the review of the literature and the practical knowledge of the sport.

The questionnaire was formatted into several groups of questions, namely the highlighted following ones:

- The characterization of the sport and its participants;

- The evaluation of the Roller Hockey existent technology;

- The perception of the impact and possibilities of the technology implementation, specifically an information system;

The questionnaire was implemented through the use of the Qualtrics platform and sent by email or social media, having the support of the FPP (Federação Portuguesa de Patinagem) to forward it to all the Roller Hockey referees ranked as International, European and National ones. The collected data was first treated using the Excel statistic tools and then further analyzed with SPSS, namely for the generation of average comparisons, factorial analysis, and variance and correlations analysis. 


\section{Results and evaluation}

In this study, 247 individuals participated, and 227 questionnaires were considered valid. The participants were identified as directly (referee, manager, coach, and athlete) or indirectly (fan) involved in this sport, belonging to the masculine or feminine gender, with ages ranging from 16 to 78 years old. The sample used included referees $(\mathrm{N}=75)$, managers $(\mathrm{N}=24)$, coaches $(\mathrm{N}=42)$, players $(\mathrm{N}=60)$, and fans $(\mathrm{N}=26)$. As the focus of this study was the technology applied to the referee role, $33 \%$ of the participants were the most directly interested in the outcome, notwithstanding the players' relevance (26\%) and coaches (19\%) opinions. As far as the gender distribution was concerned, $86 \%(\mathrm{~N}=195)$ of the individuals belonging to the sample were recorded as masculine, and only $14 \%(\mathrm{~N}=31)$ were registered as feminine.

Regarding age distribution, 69\% $(\mathrm{N}=157)$ of the respondents belonged to the range of 16 to 45 years old, and $31 \%(\mathrm{~N}=70)$ were over 45 years old.

The group of referees was the one with the most individuals above 45 years old $(\mathrm{N}=28)$, equivalent to $12 \%$ of the sampled universe and $37 \%$ of the referees questioned, while the players were the ones with the youngest participants, representing $26 \%$ of the sample $(\mathrm{N}=58)$.

Concerning academic background, referees were the ones with the lowest level, as only $20 \%$ presented a college degree, and 35\% showed only basic school attendance. On the other hand, coaches and players were the respondents with higher academic education levels, with $69 \%$ and $50 \%$ respectively showing college degrees and only 5\% and $8 \%$ respectively having completed basic school attendance. One must note that all the participants with ages ranging from 16 to 21 years old belonged to the group of athletes, which made them ineligible to have a college degree.

The 75 referees were classified according to their status during the 2019-20 season, namely, European/International Referee (15\%), Level A and B National Referee (80\%), and Regional/Apprentice Referee (5\%). The European/International referees can supervise the national championships' games, whether it be of the first, second, or third division. To ensure a high level of seniority and experience among the participant referees, the average number of years being a referee was calculated $(M=13,3)$, and the span of years of that record shown to be between 1 to 55 years.

However, when analyzed by level, this information is somewhat uneven: the referees with International or European status have an average of 22 years of experience $(M=22,1)$, while the national championships referees have an average of 12 years $(M=12,1)$, and the rest show an average of 7 years $(\mathrm{M}=7)$ of experience.
It is essential to underline that referees are under a continuous evaluation process (theoretical tests, physical tests, and performance evaluation). The final classification attributed to a referee results from the weighted average of the grades obtained along that process, which is also used to decide each referee's promotion or demotion to the adjacent level. That is why one can find national championships type of referees with only two years of experience and regional / apprentice level of referees with up to 19 years of experience.

Before evaluating the main issue, it was necessary to typify the Roller Hockey activity along four dimensions: (1) traditionality, (2) Investment, (3) social impact, and (4) promotion.

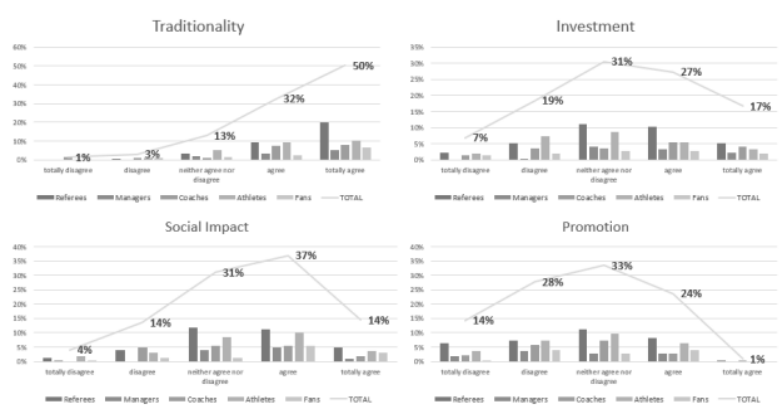

Figure 1. Roller Hockey dimensions: (1) traditionality, (2) Investment, (3) social impact and (4) promotion

The respondents have a similar perception across the four variables. They all agree that Roller Hockey is a traditional sport, with social impact and do not agree that the promotion of this sport is enough. However, there are different opinions as far as investment is concerned (see Figure 1). This divergence is correlated to the categories, levels and divisions in which the respondents are involved, as in the first division of the senior level the investment has been growing, for instance.

In order to grasp the perception people have regarding the present technologies used in this sport and the further potential applications it may have in several different situations (sport practice, support to the referees, access to information and management tools), the respondents agree with the implementation of new technologies, although revealing their satisfaction with the current level of it.

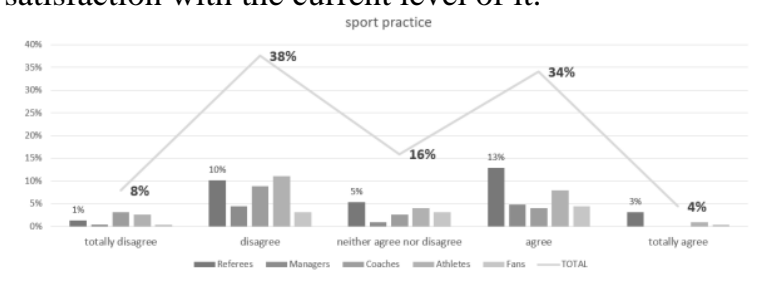

Figure 2. Current state of today's implemented technology - Sport practice 
Regarding the sports practice, the respondents do not agree that the present technology is enough (see Figure 2). This opinion is even more evident among coaches, as $12 \%$ of $19 \%$ disagree that current technology is enough for the Roller Hockey practice.

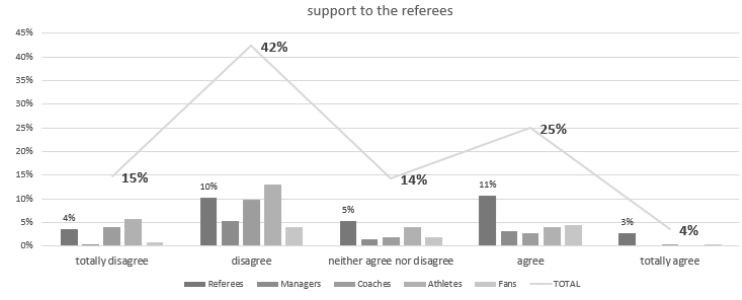

Figure 3. Current state of today's implemented technology - Support to the referees

Among the referee sampled population, it is very noticeable that their opinion is overwhelmingly disagreed that the implemented technology's current state is not sufficient. Indeed, $42 \%$ disagree, and $15 \%$ disagree (see Figure 3). Although there are several tools to help the decision-making process nowadays, it is still considered insufficient (see Figure 3). Although scarce, those tools are considered paramount and impactful, especially among its direct users, the referees (see Figure 4).

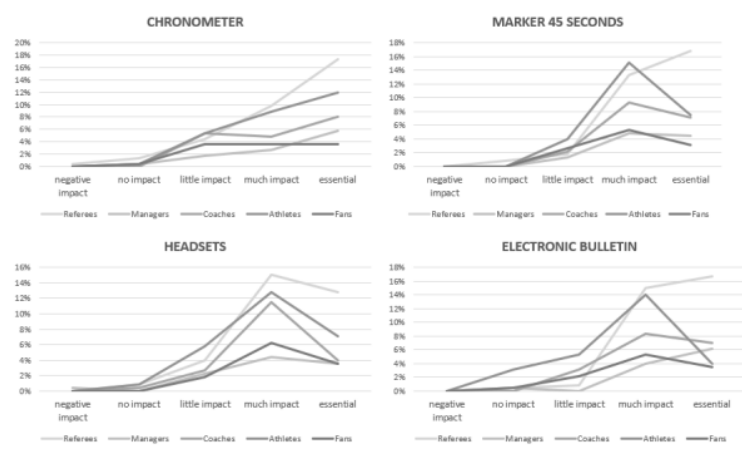

Figure 4. Tools to help the decision-making process nowadays

Portraying the group in direct contact with technologies, the referees consider of paramount importance the chronometer (17\%), the 45 seconds marker $(17 \%)$, and the electronic bulletin (17\%). As far as the earphones are concerned, the referees see them as rather significant (15\%), which can be drawn from referee teams' not using them during the World and European championships. Specifically, several Roller Hockey stakeholders disagree that it may be enough (see Figure 4).

The possible impact to Roller Hockey of other technologies used among other sports like football or tennis was analyzed.

Considering the four technologies under scrutiny (VAR, Scout, Line of Goal, and Hawk-Eye), all were labeled as positive or extremely positive, except for the Scout (virtual rendering of play movements) respondents considered to have no beneficial impact on Roller Hockey.

The VAR is considered a useful technology for football, as it enables the reviewing of doubtful moves impacting possible goals, penalties, or red-card sanctions.

Hence, it is rather pertinent to understand what the impact of this technology might be when and if applied to Roller Hockey, namely the potential to replace human intervention (the need for a second referee in the rink) and its influence on the natural fluidity of the game during its course. The respondents considered that a possible VAR implementation would not replace the need for the second referee.

The referee focus group finds the Line of Goal technology as extremely positive because it would be advantageous to prevent canceling goals due to human error (a goal is only considered valid when a ball is an eye-witnessed by a referee to have crossed the line of goal).

When crossing the implementation feasibility and the impact dimensions by analyzing the matrix table (see table 1), it is clear that the Line of Goal technology is the one with the higher implementation potential $(\mathrm{M}=4,20)$ while showing a relatively positive impact $(\mathrm{M}=4,36)$.

Table 1. Implementation and impact of VAR and LGT

\begin{tabular}{|c|l|c|c|}
\hline \multirow{2}{*}{ VAR } & Implementation & Mean & $\begin{array}{c}\text { standard } \\
\text { deviation }\end{array}$ \\
\cline { 2 - 4 } & Impact & 3,61 & 1,161 \\
\hline \multirow{2}{*}{ LGT } & Implementation & 3,73 & 1,147 \\
\cline { 2 - 4 } & Impact & 4,20 & 0,859 \\
\hline
\end{tabular}

The questionnaire was also used to wonder if the VAR technology would make the game of Roller Hockey slower and were too more comprehensive in range and too low in average $(\mathrm{M}=3,32)$ to enable a significant conclusion. However, when analyzed by a group of participants, the coaches are the ones who mostly disagree (38\%) with the possibility of the VAR implementation, while referees and the fans (44\% and $40 \%$, respectively) consider it would make the game to become slower.

The questionnaire results reveal that today's access to information is done through the internet, namely visiting specific Roller Hockey websites, such as www.FPP.pt and www.HoqueiPatins.pt (see Table 2).

Table 2. Roller Hockey's information media and websites

\begin{tabular}{|c|c|}
\hline \multicolumn{2}{|c|}{ Roller Hockey's information media } \\
\hline Internet & $100 \%$ \\
\hline FPP.pt & $69 \%$ \\
\hline HoqueiPatins.com & $85 \%$ \\
\hline Zerzero.pt & $26 \%$ \\
\hline News & $32 \%$ \\
\hline Social networks & $52 \%$ \\
\hline Others & $12 \%$ \\
\hline
\end{tabular}




\begin{tabular}{|lr|}
\hline TV & $40 \%$ \\
\hline Newspaper & $25 \%$ \\
\hline Radio & $7 \%$ \\
\hline Magazines & $3 \%$ \\
\hline Books & $6 \%$ \\
\hline Others & $6 \%$ \\
\hline
\end{tabular}

Lastly, it is clear the absence of a management application to support this sport (APP). Following the questionnaire results, it is easy to conclude that $7 \%$ of the referees assume the existence of an APP, thanks to the electronic bulletin accessible via the FPP site (see Figure 5).

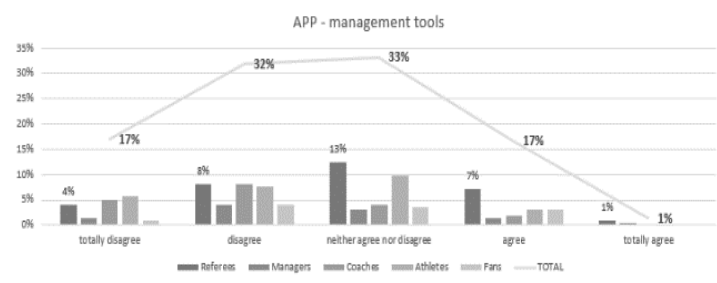

Figure 5. Current state of today's implemented technology - management tools

The present study's sample was constituted by individuals with low academic background and high age average, the risks to implement an information system must be analyzed. The electronic bulletin was used as a tech tool recently made available to support the referees' activity to assess that. The evaluation was carried out using two variables, namely the degree of difficulty during the first use and the preference for a specific type of bulletin after its usage.

Considering the degree of difficulty was concerned, half of the respondents felt it $(47 \%$ felt difficulty, $47 \%$ felt no difficulty, and $6 \%$ did not use the electronic bulletin). Considering that initial training was given to those users ( $81 \%$ said they took training), those results were not favorable. However, when assessing the referees' preference towards the electronic bulletin vis-à-vis paper one, one has to conclude that the difficulty felt during the first use was a lack of knowledge. Indeed, the referees' preference is clearly on the electronic bulletin side (93\%). There were $6 \%$ of the referees who replied with "Nonapplicable," as they have not used any electronic bulletin so far because this tool is only used in the senior level of players; only $1 \%$ of the sample showed a preference for the paper type of bulletin $(\mathrm{N}=1)$. Thus, as the referees experienced difficulties while using the electronic bulletin for the first time, one has to conclude that there are risks to the implementation of an information system for the referees of Roller Hockey; however, it was demonstrated that, once those are increasingly used, the preference goes to the more automatic and technologically evolved processes.

The game umpires were the only ones questioned concerning the management application due to their direct interaction with the system.
The management application, defined as an integrated system with all the functions used by the referee team, should have the following features/possibilities within the same physical and temporal dimension:

- To visualize the weekly appointments, with an option to confirm ones' presence;

- To apply for absentee leave and to confirm its acceptance or refusal;

- To automatically compute all the expenditures, according to the appointment details (location, level, and schedule) and to allow its forwarding;

- To consult technical delegations;

- To fill and forward each game's bulletin;

- To access FPP digital licenses, with the option to block any expulsion situation;

- To allow the Discipline Counsel to liberate any seized licenses;

- To compile the statistical data of each referee (evaluation average, games average, awarded points average, most umpired level, Etc.);

This application was evaluated as useful, appealing, and impactful to the referee teams' decision-making role (see Figure 6).

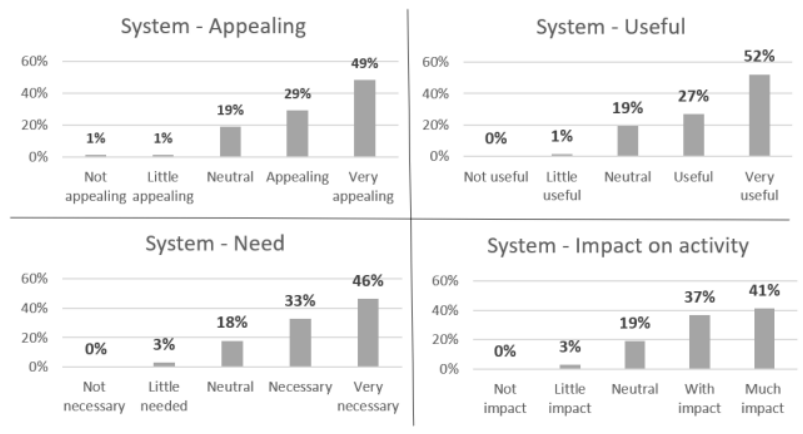

Figure 6. Classification characteristics of the information system

It was also detected that the most critical processes for a referee are access to the evaluation information and the expenditure notes issuing and forwarding. The second most critical activity is the issuing and forwarding the games' bulletins because automatic features to send those bulletins are already used today for the first and second division of the seniors' level. The very same processes were identified as necessary potential improvements (see Table 3 ).

Understandably, the implementation of an integrated information system for the referees may be seen as somewhat necessary to better deal with their job's bureaucratic processes, namely the mandatory tasks. 
Table 3. Bureaucratic processes of arbitrage

\begin{tabular}{|l|r|r|}
\hline & $\begin{array}{l}\text { Difficult } \\
\text { processes by } \\
\text { the referes }\end{array}$ & $\begin{array}{l}\text { Processes } \\
\text { possibility } \\
\text { improvement }\end{array}$ \\
\hline \hline -Waiver request & $13 \%$ & $13 \%$ \\
-Reception of calls & $2 \%$ & $5 \%$ \\
-Reception of appointments & $3 \%$ & $10 \%$ \\
-Filling in game reports & $7 \%$ & $11 \%$ \\
-Sending match results & $8 \%$ & $10 \%$ \\
-Sending match reports & $22 \%$ & $15 \%$ \\
-Access to evaluation & & \\
information & $45 \%$ & $41 \%$ \\
-Creating Expense Notes & $53 \%$ & $66 \%$ \\
-Sending expense notes & $47 \%$ & $70 \%$ \\
\hline
\end{tabular}

On top of this, it is also important to note how the data from the inquiry shows a clear preference for an electronic game's bulletin. Indeed, $93 \%$ of the referees prefer an electronic version instead of the paper one (see Table 4).

Table 4. Referee preference bulletin

\begin{tabular}{|l|r|}
\hline Paper Bulletin & $1 \%$ \\
\hline Electronic Bulletin & $93 \%$ \\
\hline Not applicable & $6 \%$ \\
\hline
\end{tabular}

Lastly, it is vital to perceive if the direct participants in Roller Hockey are available to implement technology in the sport and note that all are available (see table 4).

Table 5. Availability to implement technology at Roller Hockey

\begin{tabular}{|c|c|c|c|}
\hline & & Mean & $\begin{array}{c}\text { Std. } \\
\text { Deviation }\end{array}$ \\
\hline \multirow{5}{*}{ 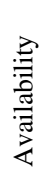 } & Referees & 4,04 & 0,821 \\
\hline & Managers & 3,75 & 0,851 \\
\hline & Coaches & 4,07 & 0,740 \\
\hline & Players & 4,10 & 0,721 \\
\hline & Fans & 3,70 & 0,877 \\
\hline
\end{tabular}

The direct participants of Roller Hockey are most available to implement technology in this sport, as referees, coaches, and players consider themselves to be very available $(\mathrm{M}=4,04, \mathrm{M}=4,07$, and $\mathrm{M}=4.10$, respectively) (see Table 5).

\section{Conclusion}

Considered a traditional sport with low investment and promotion, Roller Hockey lacks a technological quantum leap that will bring more efficiency to the multiple entities involved. The constant introduction of new technologies in sports with high investments makes them more appealing to the general public. The results obtained through this study conclude that
Roller Hockey has a significant margin to become more attractive to the general public and stakeholders through the investment in technologies, namely information and management technological systems.

It was demonstrated that the referees, a group of participants in this sport with a high average age level and low academic background, consider relevant the implementation of new technologies, as the impact would be very positive, namely to better support their decision-making tasks.

The future introduction of an information system tailored to this sport is perceived as useful, necessary, and appealing. The same conclusion is reached regarding the manifested preference for an electronic bulletin, although current procedures such as a second referee's existence in the rink should be kept.

Globally, we concluded that the tailored implementation to Roller Hockey of other sports already existing and successful technologies are perceived as positive. That evolution has the potential to bring higher levels of transparency to the practice of this sport. It will, for sure, be an inevitable and essential trend in the Roller Hockey sport soon. High necessary investments for the application of technology will be the main obstacle to overcome so that Roller Hockey may continue to grow as far as the number of athletes and fans is concerned, and the sport may reach higher levels of recognition in the general sportive landscape, where only a few numbers of sports are the focus of the majority of attention and media coverage.

\section{References}

[1] APLisboa. (s.d.). APRIBATEJO.http://www.apribatejo. com/index.php/hoquei-em-patins/sobre-a-modalidade.

(Accessed Date: 31 December, 2019).

[2] Brito, I., 2010. A Flexibilidade no Hóquei em Patins. Escola Superior de Tecnologia da Saúde do Porto.

[3] Covell, D., Walker, S., and Hess, P. W., 2007. Managing Sport Organizations: Responsibility for performance. Butterworth-Heinemann.

[4] Fowler, S., 2013. How Feasible is Officiating Technology in Football? University of Southampton.

[5] Furtado, T. S., 2005. Adaptação da prova de patamares progressivos de corrida contínua a patins (3P2CP). Universidade de Coimbra.

[6] Galak, E., Zoboli, F., and Junior, H. S., 2018. O ÁRBITRO DE VÍDEO: POLÍTICA, FUTEBOL E CORPOS EM IMAGENS (EM MOVIMENTO). Universidad Nacional de La Plata.

[7] Garganta, J., 2001. Revista Portuguesa de Ciências do Desporto. A análise da performance nos jogos desportivos. Revisão acerca da análise do jogo. Universidade do Porto, pp. $57-64$. 
[8] Gayo, A. A., 2000. El hockey sobre patines como deporte de equipo. Análisis y optimización de los sistemas de juego a través de indicadores tácticos. Universidade da Coruña.

[9] Gonçalves, C., 2005. Posicionamento das Modalidades Desportivas Federadas: Andebol, Basquetebol, Hóquei em Patins e Voleibol. Universidade Técnica de Lisboa.

[10] Hoye, R., and Parente, M. M., 2016. The SAGE Handbook of Sport Management. SAGE Publications Ltd.

[11] Katz, L., 2002. Revista EF. Inovações na Tecnologia Esportiva: Implicações para o Futuro, Canada, pp. 27 - 32.

[12] Leveaux, R., 2010. Communications of the IBIMA. Facilitating Referee's Decision Making in Sport via the Application of Technology, Istambul, Turquia, pp. 1 - 8.

[13] Liparotti, J. R., 2016. UFRN na Copa apresenta: O que sabemos sobre o futebol. edufrn.

[14] Lopes, R., 2019. A gestão desportiva na modalidade futebol. Universidade do Porto.

[15] Morais, J. V., and Barreto, T. V., 2008. As regras do futebol e o uso de tecnologias de monitoramento. Universidade Federal de Pernambuco, Brasil.

[16] Pinheiro, F., 2011. Fazer História do Desporto. Paradigmas e Problemáticas. Universidade de Coimbra.

[17] Sénica, L., 2011. Organização e Planeamento do treino de Hóquei em Patins em equipa de Alto Rendimento. Universidade Lusófona de Humanidades e Tecnologias.

[18] Valente, C., 2018. Tecnologias e Sistemas de Informação no Desporto, uma revisão sistemática da literatura. Universidade de Lisboa.

[19] Vendite, C. C., Vendite, L. L., and Carlos de Moraes, A., 2005. XXVIII Congresso Brasileiro de Ciências da Comunicação. Scout No Futebol: Uma Ferramenta Para a Imprensa Esportiva. Universidade do Estado do Rio de Janeiro.

[20] Viseu, J., 2002. Política - Inovação - Desporto: Uma análise crítica sobre o setor do desporto em Portugal. Universidade de Aveiro. 